\title{
Electron Spin Resonance Study on Plasma-Induced Surface Radicals of Ethylene-Tetrafluoroethylene Copolymer
}

\author{
Masayuki KuzuYa,* Junji Niwa, and Tadashi NoguchI \\ Laboratory of Pharmaceutical Physical Chemistry, Gifu Pharmaceutical University, \\ 5-6-1, Mitahora-Higashi, Gifu 502, Japan
}

(Received August 10, 1994)

\begin{abstract}
We have undertaken Ar plasma irradiation on ethylene-tetrafluoroethylene $(1: 1)$ alternating copolymer (ETFE) powder, and the radicals formed were studied by electron spin resonance (ESR). The room temperature ESR spectrum of plasma-irradiated ETFE shows a six-line spectrum (sextet) similar to that of polyethylene (PE), due to a small difference in hyperfine splitting constant between $\beta-\mathrm{H}$ and $\beta$-F atom. Thus, the major radical formed was assigned to the midchain alkyl radical generated by hydrogen elimination. The ESR spectral parameters for a representative sextet deduced from the simulated spectra are as follows: $g=2.0029, N_{\alpha}=2.19 \mathrm{mT}(1 \mathrm{H}), H_{\beta}=$ $2.88 \mathrm{mT}(2 \mathrm{H})$, and $F_{\beta}=2.80 \mathrm{mT}(2 \mathrm{~F})$. It was also found that the sextet spectrum gradually turned toward a broad single-line spectrum as the plasma duration increased indicating the successive formation of dangling bond sites (DBS) due to the occurrence of cross-linked surface reaction.

KEY WORDS Plasma-Irradiation / Solid Radical / Ethylene-Tetrafluoroethylene Copolymer / Electron Spin Resonance Spectroscopy /
\end{abstract}

It is well known that plasma-irradiation effectively creates a large amount of stable free radicals on the polymer surface, which permit reactions for surface modifications in several different ways such as CASING, surface graft polymerizations and incorporation of functional groups (plasma-treatment). ${ }^{1}$ However, most of such research had been made on the surface analyses by various kinds of physical methods after the surface radicals underwent the termination reactions to stable diamagnetic molecules, and the detailed ESR studies of such surface radicals had not been worked out. We believe that the study on the nature of plasma-induced polymer radical formation is of fundamental significance to understand the molecular mechanism of "plasma-treatment," and provide a basis for the future experimental design on various kinds of polymers. We have recently reported that detailed ESR studies on the nature of radical formation induced by $\mathrm{Ar}$ plasma-irradiation in several kinds of organic polymers. $^{2-15}$ Among these studies, it was found with the aid of computer simulations that the spectra of plasma-irradiated PE and polytetrafluoroethylene (PTFE) were outlines of multicomponent spectra. The spectrum of plasma-irradiated PE powder consists essentially of the midchain alkyl radical (1), the allylic radical (2) and dangling bond sites (DBS) (3), respectively. ${ }^{2}$

$$
\begin{array}{cc}
-\mathrm{CH}_{2}-\dot{\mathrm{C}} \mathrm{H}-\mathrm{CH}_{2}- & -\mathrm{CH}_{2}-\mathrm{CH}=\mathrm{CH}-\dot{\mathrm{C}} \mathrm{H}-\mathrm{CH}_{2}- \\
\begin{array}{c}
\text { Midchain alkyl } \\
\text { radical (1) }
\end{array} & \text { Allylic radical (2) }
\end{array}
$$

The spectrum of plasma-irradiated PTFE powder consists essentially of the midchain alkyl radical (4), the endchain alkyl radical (5) and DBS (6), respectively. ${ }^{3}$

$$
-\mathrm{CF}_{2}-\dot{\mathrm{C}} \mathrm{F}-\mathrm{CF}_{2-}
$$$$
-\mathrm{CF}_{2}-\dot{\mathrm{C}} \mathrm{F}_{2}
$$

Midchain alkyl radical (4) Endchain radical(5)

In order to gain an insight into the copolymerization effect on the nature of plasma- 
induced surface radical formation, we have undertaken Ar plasma irradiation on ethylenetetrafluoroethylene alternating copolymer (ETFE) powder, and the radicals formed were studied by ESR spectral measurement.

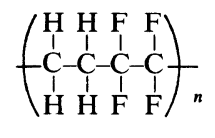

ETFE

\section{EXPERIMENTAL}

\section{Plasma-Irradiation and ESR Spectral Measure- ment}

ETFE powder (Asahi Glass Co., particle size $20 \mu \mathrm{m}, 100 \mathrm{mg}$ ) was placed in a specially designed ampule (30 mm i.d., $100 \mathrm{~mm}$ long) connected with capillary tube $(2 \mathrm{~mm}$ i.d.) at the upmost part of the ampule and the ampule was filled with Ar gas and sealed (0.5 Torr). Then the plasma state of Ar was sustained at the upper part of the ampule by stirring the samples by a radio frequency discharge of inductively coupled plasma (ICP) at 13.56 $\mathrm{MHz}$ using a four loop antenna with the supplied power $(40 \mathrm{~W})$ for a prescribed period of time. The procedure for plasma-irradiation was essentially the same as that reported earlier. $^{2}$

The ESR spectral intensity was determined by double integration. The radical concentration (spin numbers $/ \mathrm{cm}^{2}$ ) was calculated from the spectral intensities with the aid of calibration lines obtained from the spectral intensity of a poly(methylmethacrylate) powdered sample impregnated with DPPH. Measurements of $g$-values were made relative to the fourth signal from the lower magnetic field $(g=1.981)$ of $\mathrm{Mn}^{2+}$ in magnesium oxide $(\mathrm{MgO})$. ESR spectra were recorded by a JESRE1X (JEOL) spectrometer with X-band and $100 \mathrm{kHz}$ field modulation. Care was taken to ensure that no saturation occurred and that the line shape was not distorted by an excessive modulation amplitude. Thus, from a plot of the square root of the microwave power versus the signal peak height, a power level of 0.04 $\mathrm{mW}$ was chosen.

\section{Computer Simulation of ESR Spectra}

The computer simulations were performed using a 32-bit microcomputer (NEC PC9801FA). The simulated spectra were obtained from Gaussian functions by iteratively fitting spectroscopic parameters ( $g$-value, line width at half-height (HV), hyperfine splitting constant (HSC), and relative peak intensity) with the observed spectra digitized through an A/D converter according to a nonlinear least squares method. ${ }^{4}$ The simulation programs were fabricated so as to include the effect of $g$-factor anisotropy and/or $\alpha$-hydrogen anisotropy on the line shape of the powder spectra according to Kneubühl's equation and Cochran's equation, respectively. ${ }^{16}$

To assist the simulation procedure, we have also fabricated a program obtaining the difference spectrum by subtracting one observed spectrum from another.

\section{RESULTS AND DISCUSSION}

\section{Observed Room Temperature ESR Spectra of Plasma-Irradiated ETFE Powder}

The progressive changes of the room temperature ESR spectra of plasma-irradiated ETFE powder with various plasma durations are shown in Figure 1, together with the corresponding simulated spectra. It is seen from Figure 1A that even less than several seconds plasma irradiation is long enough to detect the radicals formed. The room temperature ESR spectrum of plasma-induced radicals of ETFE shows a well-defined sextet spectrum similar to that of $\mathrm{PE},{ }^{2}$ but not with a binomial intensity distribution. It is apparent that the spectral intensity increases as the plasma duration increases, but the sextet spectral pattern has gradually changed, especially characterized by a lowering of the peak height of the fourth line from the left relative to that of the third line. 


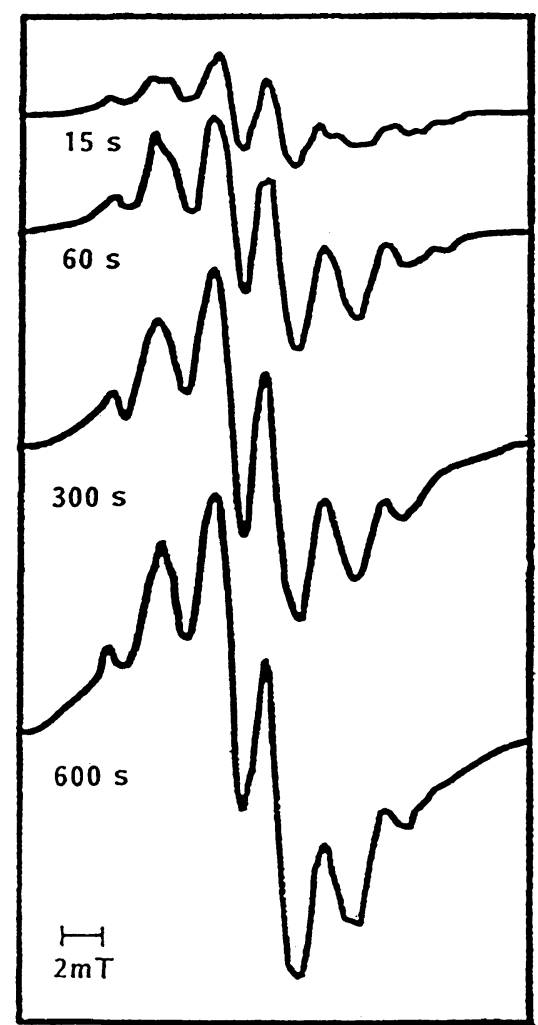

A

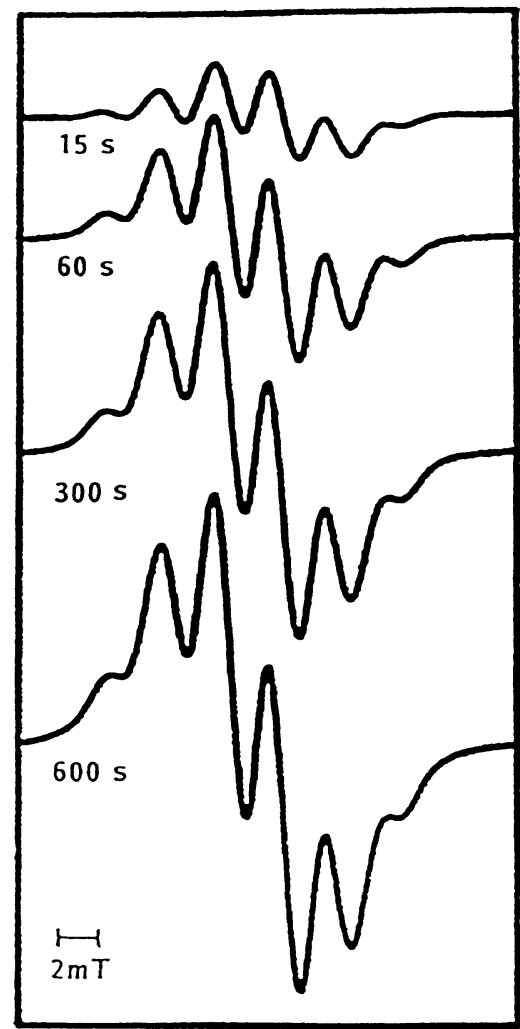

B

Figure 1. Observed and simulated spectra of Ar plasma-irradiated ETFE powder with various plasma duration. A, Observed; B, Simulated.
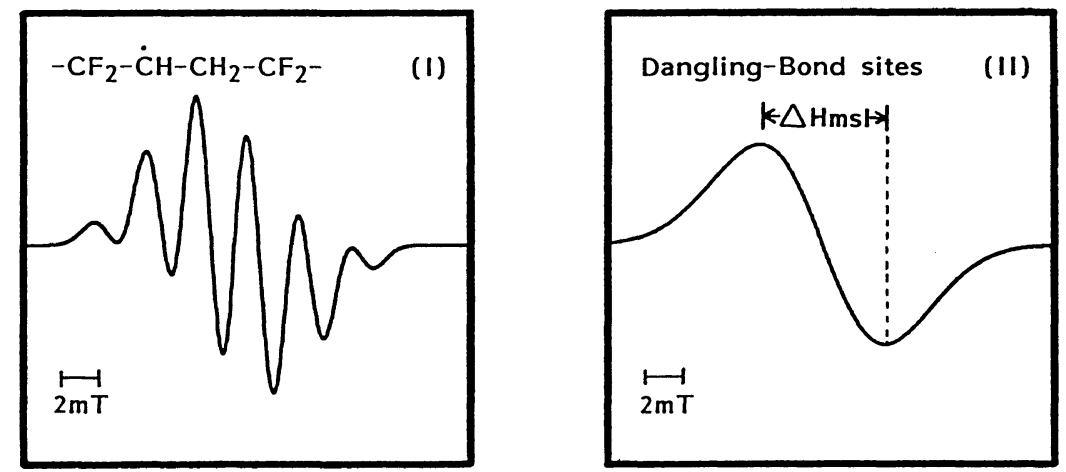

Figure 2. Representative spectral features for the two component spectra I and II in the simulated spectra.

\section{Simulated Spectra}

The corresponding simulated spectra are shown in Figure 1B. It can be seen that all the observed spectral features have been satisfactorily reproduced by the simulation. The simulated spectra consist principally of two 
kinds of spectra; an isotropic sextet spectrum (I), and a broad single line spectrum (II) (Figure 2).

The major sextet spectrum (I) is apparently similar to that of $\mathrm{PE}$, and assigned to the midchain alkyl radical generated by hydrogen elimination, due to a small difference in hyperfine splitting constant between $\beta$ - $\mathrm{H}$ and $\beta$-F atom. The ESR spectral parameters for a representative sextet spectrum deduced from the simulated spectra are as follows: $g=2.0029$, $H_{\alpha}=2.19 \mathrm{mT}(1 \mathrm{H}), H_{\beta}=2.88 \mathrm{mT}(2 \mathrm{H})$, and $F_{\beta}=2.80 \mathrm{mT}(2 \mathrm{~F})$.

The progressive changes of the component spectral intensities of plasma-induced ETFE radicals deduced from the simulated spectra are shown in Figure 3.

It is seen that the intensities of all components spectra increase almost linearly at initial stages, but the intensity of a broad single line spectrum (II) tends to level off at longer plasma duration.

\section{Nature of Plasma-Induced ETFE Radicals}

We can summarize the formation of plasma-induced ETFE radicals according to Scheme 1. Plasma irradiation causes hydrogen atom elimination to produce a midchain alkyl radical (I). There seems to be three available pathways for the alkyl radicals.
First, a $\beta$-hydrogen may be eliminated to give a vinylene group in the polymer main chain. The formation of a vinylene group at PE facilitates a hydrogen atom elimination to give allylic radical, but in ETFE it does not undergo a fluorine atom elimination or migration because of larger $\mathrm{C}-\mathrm{F}$ bond dissociation energy. The second channel is a $\beta$-scission of $\mathrm{C}-\mathrm{C}$ bond. This pathway produces the endchain radical possessing a $\alpha$-fluorine atom. The third channel is radicalradical coupling and/or the reaction of the radical with unsaturated bonds to lead to the

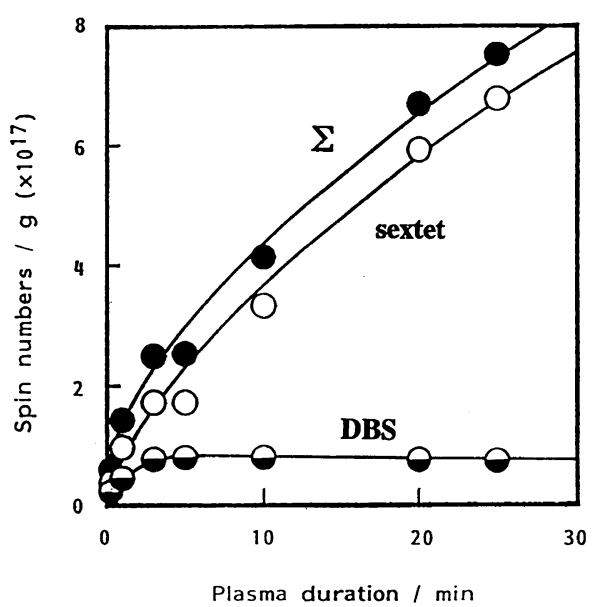

Figure 3. Progressive changes in component spectra of Ar plasma-irradiated ETFE powder.

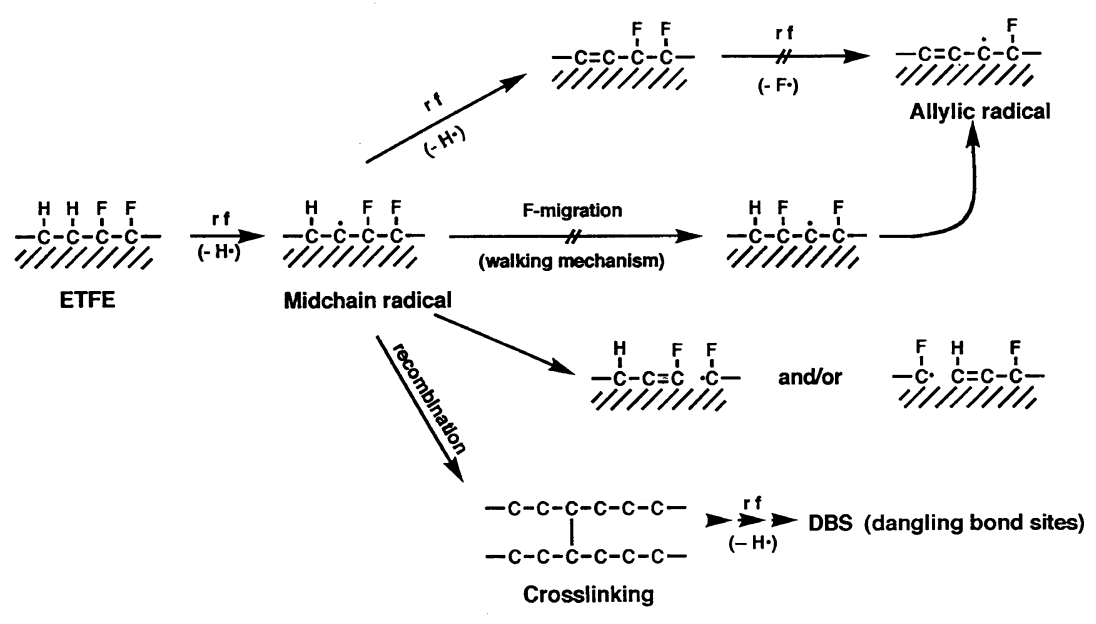

Scheme 1. 
formation of the cross-linked portion. Repetition of all the above reactions produces the highly cross-linked network at the polymer surface containing the immobilized DBS at the polymer surface. In view of the fact that the DBS of a broad single line in the simulated spectra shows a large peak-to-peak width $\left(\Delta H_{\mathrm{msl}}\right)$ of $c a .7 .0 \mathrm{mT}$ (Figure 2), the carboncentered radicals bearing a $\alpha$-fluorine atom are present in the DBS.

\section{REFERENCES}

1. M. Huidis, in "Techniques and Applications of Plasma Chemistry," J. R. Hollahan and A. T. Bell, Ed., Wiley, New York, N.Y., 1974.

2. M. Kuzuya, J. Niwa, and H. Ito, Macromolecules, 26, 1990 (1993).

3. M. Kuzuya, H. Ito, S. Kondo, N. Noda, and A. Noguchi, Macromolecules, 24, 6612 (1991).

4. M. Kuzuya, A. Noguchi, M. Ishikawa, A. Koide, K. Sawada, A. Ito and N. Noda, J. Phys. Chem., 95, 2398 (1991).
5. M. Kuzuya, A. Noguchi, H. Ito, S. Kondo, and N. Noda, J. Polym. Sci., A, Polym. Chem., 29, 1 (1991).

6. M. Kuzuya, K. Kamiya, and K. Sawada, Proc. Jpn. Symp. Plasma Chem., 4, 317 (1991).

7. M. Kuzuya, M. Ishikawa, A. Noguchi, K. Sawada, and S. Kondo, J. Polym. Sci., A, Polym. Chem., 30, 379 (1992).

8. M. Kuzuya, S. Kondo, H. Ito, and A. Noguchi, Appl. Surf. Sci., 60/61, 416 (1992).

9. M. Kuzuya, N. Noda, S. Kondo, K. Washino, and A. Noguchi, J. Am. Chem. Soc., 114, 6505 (1992).

10. M. Kuzuya, K. Sawada, T. Takai, and A. Noguchi, Polym. J., 25, 75 (1993).

11. M. Kuzuya, K. Kamiya, Y. Yanagihara, and Y. Matsuno, Plasma Sources Sci. Technol., 2, 51 (1993).

12. M. Kuzuya, S. Kondo, A. Noguchi, and K. Xu, $J$. Photopolym. Sci. Technol., 6, 371 (1993).

13. M. Kuzuya, J. Niwa, Y. Yamauchi, and S. Kondo, J. Photopolym. Sci. Technol., 7, 315 (1994).

14. M. Kuzuya and J. Niwa, Proc. Jpn. Sym. Plasma Chem., 7, 59 (1994).

15. M. Kuzuya, K. Morisaki, J. Niwa, Y. Yamauchi, and K. Xu, J. Phys. Chem., 98, 11301 (1994).

16. (a) F. K. Kneubühl, J. Chem. Phys., 33, 1074 (1960). (b) E. L. Cochran, F. J. Adrian, and V. A. Bowers, J. Chem. Phys., 34, 1161 (1961). 